\title{
MARK LILLA:
}

PENSADORES TEMERARIOS. LOS INTELECTUALES EN LA POLÍTICA.

Barcelona, Debate, 2017, 207 PÁGs.

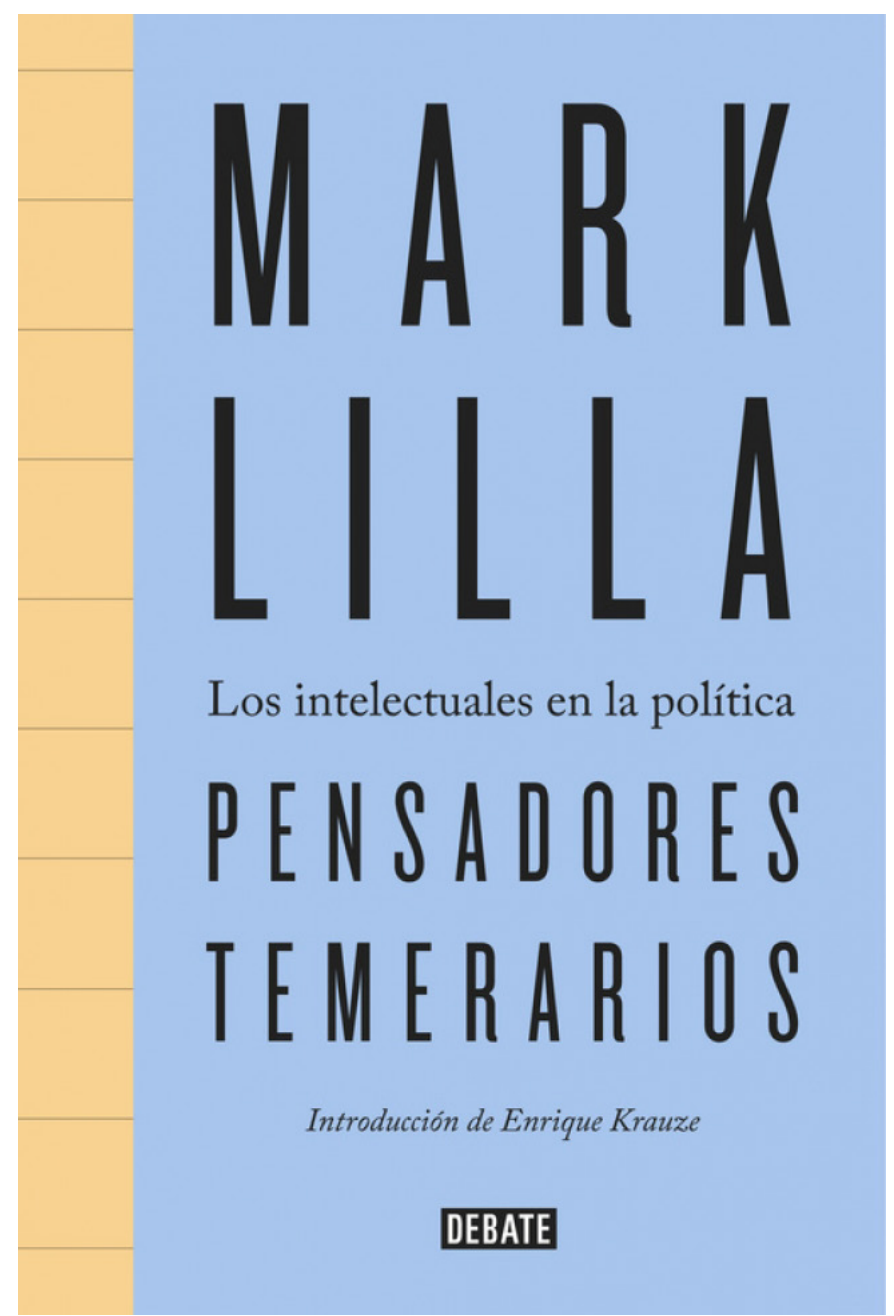


Mark Lilla (Detroit, 1956), ensayista e historiador del pensamiento político, especializado en la herencia de la Ilustración, ejerce en la actualidad como Profesor de Humanidades en la Universidad de Columbia, donde colabora frecuentemente en medios como el New York Review of Books, New Republic y The New York Times. Es autor de El Dios que no nació (Debate, 2010) y La mente naufragada (Debate, 2017). La edición en español de su obra Pensadores temerarios. Los intelectuales en la política, incluye una introducción, "El intelectual filotiránico”, de Enrique Krauze, así como un prefacio del autor en el que presenta los seis capítulos de esta obra, en los que se ocupa del recorrido vital e intelectual de Martin Heidegger - Hannah Arendt - Karl Jasper, Carl Schmitt, Walter Benjamin, Alexandre Kojève, Michel Foucault y Jacques Derrida. El libro finaliza con dos epílogos y un índice alfabético.

En la "Introducción: El intelectual filotiránico", Enrique Krauze nos explica que Mark Lilla es un heredero de la Ilustración inglesa y el humanismo alemán, formado en Harvard y discípulo del sociólogo Daniel Bell; un liberal clásico que milita contra el relativismo moral y reivindica el lugar de las instituciones democráticas, el papel de la tolerancia, la necesidad del Estado de derecho y las libertades cívicas. Nos dice Krauze que la presente obra de Lilla analiza la trayectoria de varios influyentes pensadores que sucumbieron a la fascinación del poder totalitario, sus líderes o sus ideologías mesiánicas. Tras seis ensayos independientes, el epílogo, "La seducción de Siracusa" unifica los seis textos y propone una explicación a esa atracción que Lilla llama "filotiranía".

En el "Prefacio" Lilla, al hilo de la obra de Czeslaw Milosz publicada en 1953, El pensamiento cautivo, boceta una serie de preguntas tales como: ¿Cómo explicamos la existencia de coros prodictatoriales en aquellos países donde los intelectuales no se enfrentaban a ningún peligro y donde eran libres de escribir lo que les diese la gana? ¿Qué les habrá inducido a ellos a justificar los actos de las tiranías modernas o, de modo más común, a negar toda diferencia esencial entre las tiranías y las sociedades libres de Occidente? ¿Cómo trabajan esas mentes? ¿Y qué buscan en la política? Este libro, dice Lilla en su "Prefacio", pretende dar respuesta a esas preguntas y puede ser leído como un modesto compañero de $E l$ pensamiento cautivo de Milosz.

En el capítulo 1 "Martin Heidegger - Hannah Arendt - Karl Jaspers" Lilla nos presenta uno de los episodios más extraordinarios 
de la vida intelectual de nuestro tiempo: el amor y la amistad entre estos tres pensadores que se conocieron hacia 1920 sintiéndose atraídos a causa de su común pasión por la filosofía. Más allá de que Arendt y Heidegger fuesen episódicamente amantes, a Lilla lo que le resulta más importante es de qué modo, ante la seducción moderna de las dictaduras, cada uno de ellos planteó el lugar de la pasión en la vida del pensamiento. Nos dice Lilla que el affaire entre Heidegger y Arendt fue inicialmente desvelado en Hanna Arendt: For Love of the World (1984), una biografía escrita por Elisabet Young-Bruehl. Unos años más tarde, el asunto se transformó en objeto de desagradable polémica tras la publicación del estudio de Elzbieta Ettinger, Hanna Arendt/Martin Heidegger (1995). Con este estudio, la profesora Ettinger deseaba crear un escándalo, y lo consiguió. Ettinger describió la relación entre ambos como un vínculo con profundos rasgos patológicos, que duraría desde el primer encuentro en 1924 hasta la repentina muerte de Arendt en 1975. Lilla concluye que el libro de Ettinger mostraba una evidente falta de responsabilidad. No obstante, el escándalo estaba servido. Dicha correspondencia fue publicada en una edición alemana. El volumen pone la relación de ambos en un nuevo marco intelectual: la amistad filosófica desarrollada y compartida con su amigo en común, el pensador existencialista Karl Jaspers. En 1920, Karl Jaspers conoció a Heidegger. La fama de Jaspers se gestó gracias a Psicología de las concepciones del mundo, publicado en 1919. La relación se consolidó en 1922, cuando Jaspers invitó a Heidegger a pasar una semana con él en Heidelberg. En 1923, Heidegger se trasladó a Marburgo para tomar posesión de su primer cargo académico independiente: allí reunió a un grupo de estudiantes llegados de toda Europa para estudiar con él. Una de esas alumnas esa Hannah Arendt.

Arendt había nacido en 1906 en la Prusia oriental, y sólo tenía dieciocho años cuando llegó a Marburgo. En algún momento, durante ese semestre, brotó la pasión entre Heidegger y Arendt; su correspondencia, que empieza en febrero de 1925, deja claro que por aquel entonces ya había pasado algo entre ellos. Inevitablemente, Arendt se rebela contra las restricciones de su amor prohibido y a principios de 1926 decide trasladarse a Heidelberg, donde terminará sus estudios con Karl Jaspers, un gesto que Heidegger aprobó. En 1927 se publicó Ser y tiempo, con tal aceptación que al año siguiente su autor recibió una invitación para ocupar la cátedra de Husserl en Friburgo. Un año mas tarde, Arendt se casaría con Günther Stern, 
trasladándose con él a Frankfurt. Durantelos años siguientes, las vidas delos tres amigos y amantes se desarrollaron de manera independiente y sin incidentes destacables. En 1929, Arendt publicaría su tesis doctoral, El concepto de amor en san Agustín, bajo la dirección de Jaspers. En 1933 Heidegger se convirtió en rector de la Universidad de Friburgo y se unió al partido nazi. En cuanto a Arendt, escapó a Paris junto a su marido. En Francia pasó, en condiciones precarias, los siguientes siete años, hasta que se vio forzada a huir a Estados Unidos. Llegó a Nueva York en 1941, mientras la guerra se extendía por Europa, y finalmente perdió todo contacto tanto con Heidegger como con Jaspers. Ellos continuaron intercambiando libros y notas hasta 1937, cuando Jaspers fue separado de su cargo y se vio limitado a sobrevivir hasta el fin de la guerra, en su calidad de antinazi casado con una mujer judía e impedidos ambos de abandonar el país. En 1945, un comité de desnazificación decidió apartar a Heidegger de la enseñanza y privarlo de su pensión.

En 1948, Jaspers se trasladó a Suiza, donde pasaría el resto de su vida. La amistad entre ambos se rompió. En torno a 1950, Arendt realizó un extenso viaje por Europa, comisionada por la Agencia para la Reconstrucción Cultural Judía, poco antes de la publicación, en 1951, de su monumental Los orígenes del totalitarismo. En febrero de 1950, su cometido la llevó a Friburgo, donde se reencontró con Heidegger. En el siguiente año, Heidegger retomó la correspondencia, enviando a Arendt diecisiete cartas y treinta y dos poemas. El hielo se rompió definitivamente en 1967, cuando se reencontraron en una conferencia que Arendt ofrecía en Friburgo. Desde ese momento y hasta la repentina muerte de Arendt en 1975, mantuvieron una relación amistosa. A diferencia de Jaspers, Arendt nunca se enfrentó a Heidegger de manera directa en cuestiones políticas. Por su parte, Jaspers se sentía traicionado por Heidegger, como ser humano, como alemán y como amigo, pero especialmente como filósofo.

El profesor Lilla dedica el capítulo 2 a "Carl Schmitt”, quien nació en Westfalia, donde murió en 1985, a los noventa y seis años. Hoy es considerado en Europa y especialmente Alemania uno de los más significativos teóricos políticos del siglo XX. Ni siquiera la activa colaboración de Schmitt con el régimen nazi ha disminuido el interés por el hombre y sus escritos. El 1 de mayo de 1933, mientras era profesor de derecho en la Universidad de Colonia, Schmitt se afilió al partido nazi. Durante el decenio siguiente se convirtió en un destacado jurista y político antiliberal y en un tenaz crítico del Tratado 
de Versalles y de la Constitución de la república de Weimar. Bajo el patrocinio de Hermann Göring, fue nombrado miembro del Consejo de Estado prusiano, le fue otorgada una cátedra en la universidad de Berlín y editaba una influyente revista jurídica.

A pesar de sus intentos por mantener su influjo y reputación dentro del régimen, mientras la guerra se volvía total, fue casi completamente olvidado. Perdió la mayoría de sus privilegios oficiales, aunque continuó enseñando en Berlín hasta el fin de la guerra. Tras ser arrestado, primero por los rusos y luego por los estadounidenses, fue enviado a Nuremberg para ser interrogado. Finalmente fue liberado y retornó a su ciudad natal. Nunca volvió a la docencia. Hasta el día de su muerte, Schmitt se negó a hacer gesto alguno de arrepentimiento por su colaboración con el régimen nazi. Después de la guerra, lejos de caer en el olvido, su influjo fue haciéndose mayor. Durante los diez años anteriores a su muerte, se convirtió en uno de los intelectuales más intensamente discutidos de Alemania. Hay muchas razones para que las obras políticas de Schmitt sigan estudiándose en la actualidad. Una de ellas es que sus preocupaciones políticas (soberanía, unidad nacional, el peligro de ignorar la enemistad de las naciones, la guerra, la estabilidad constitucional) han vuelto a ser temas centrales de la política europea. La otra razón de su renombre es que se cuenta entre los pocos teóricos políticos involucrado con cada una de las cuestiones que Alemania ha tratado en el siglo XX y el único de ellos que se mantuvo activo después de la guerra. Que Schmitt considerara su apoyo a los nazis como un mero error táctico es totalmente consecuente con su teología política. Su idea romántica de las instituciones católicas, su admiración por Mussolini, su intento de rescatar una legitimidad democrática del legalismo del sistema de Weimar y su militancia a favor de Hitler, aunque no fuese sistemática, reflejan la voluntad de animar a todo aquel que esté dispuesto a presentar batalla contra la secularizada época liberal.

El capítulo 3 de este ensayo lleva por título "Walter Benjamin", autor al que nos acercarán estas líneas. En 1968, Hanna Arendt editó Illuminations, primera selección inglesa de los ensayos de Walter Benjamin. Hasta entonces, fuera de Alemania se sabía muy poco de su autor, excepto que había sido un crítico con gran talento y que se había suicidado huyendo de los nazis en 1940. Los ensayos seleccionados por Arendt reflejan sobre todo sus logros literarios, aunque los dos últimos dan alguna noción sobre el profundo calado filosófico de Benjamin. Cuando apareció Iluminaciones, ya se había 
iniciado en Alemania un acalorado debate en torno al alcance de su obra. Theodor Adorno y su mujer, Gretel habían sido los editores de la primera selección de las obras de Benjamin, a mediados de los cincuenta. Treinta años después, los Adorno sufrirían el ataque de la nueva izquierda alemana, que los acusaban de haber atenuado el marxismo revolucionario de Benjamin al expurgar sus textos. Esta polémica se intensificó cuando Theodor Adorno y el historiador judío Gershom Scholem editaron conjuntamente una selección de su correspondencia. Aunque Walter Benjamin se había declarado marxista desde 1920 hasta su muerte, las cartas mostraban cómo la cuestión teológica lo había preocupado profundamente. Lo que en Alemania había comenzado como una discusión sobre el legado de Benjamin se convirtió pronto en una significativa controversia sobre la relación entre las ideas políticas y las teológicas.

Walter Benjamin nació en 1892, en el seno de una adinerada familia judía de Berlín. Muy pronto, comenzó a escribir para uno de los periódicos del Movimiento de la Juventud, Der Anfang, y mantuvo una relación con Wyneken y el movimiento pedagógico "nietzscheano" hasta la I Guerra Mundial. Cuando la guerra irrumpió en su vida, y después de que Wyneken publicara el manifiesto nacionalista "La juventud y la guerra", Benjamin decidió alejarse de su antiguo maestro y del Movimiento de la Juventud. En 1917 partió a Suiza, junto con su esposa Dora, y en 1918 comenzó un intenso intercambio intelectual con Gershom Scholem quien le contagió "la devoción por lo espiritual". La publicación en Alemania de la correspondencia de Benjamin atrajo por primera vez la atención hacia sus primeros escritos filosóficos, con su fuerte trasfondo teológico. Tanto Benjamin como Scholem habían comenzado sus estudios filosóficos leyendo a Kant. Benjamin tomó como desafío filosófico superar la distinción que hace Kant entre el mundo fenoménico de la ciencia y el mundo nouménico de los fines morales, dentro del marco que le brindaba el propio pensamiento kantiano, que denomina "la tarea central de la filosofía futura". Benjamin era consciente de que transitaba por las sendas del romanticismo, y durante los años posteriores se propuso enfrentarse a ello directamente. Lo hizo en su primera disertación erudita, El concepto de crítica de arte en el romanticismo alemán, que fue aceptada por la facultad de Berna en 1919. En ella argumentaba que la crítica puede alcanzar una potencia tal que sea capaz de volverse más valiosa que la misma creación. En 1920, la situación económica alemana lo obligó a dejar Suiza. En 
1921, Benjamin y su esposa Dora se enamoraron de otras personas y, finalmente, la pareja se divorció en 1930.

En 1929 publicó "Crítica de la violencia”, un ensayo en torno a Reflexiones sobre la violencia de George Sorel. Su "Fragmento teológico-político”, escrito un año más tarde, no deja de ser apocalíptico. Luchar por el fin del mundo natural es, afirma Benjamin, "la tarea de la política del mundo, cuyo método podría ser llamado nihilismo". El concepto de Benjamin de la crítica como alquimia, su convicción de que la política es un asunto de nihilismo apocalíptico y su fascinación por el vitalismo de derechas dieron lugar al nacimiento de su obra más importante del decenio de 1920, Ursprung des deutschen Trauerspiel (El origen del drama barroco). El propio Benjamin reconoce que las reflexiones políticas y teológicas desarrolladas en esta obra habían encontrado su inspiración en las ideas de Carl Schmitt, teórico derechista y funcionario del gobierno nazi, al que Lilla le dedicó el capítulo anterior de la obra que nos ocupa. Todavía en 1930, tiempo después de que se hubiese convertido al marxismo y trabajara en colaboración con Brecht, Benjamin dedicó un ejemplar de $E l$ origen del drama barroco alemán a Schmitt, proclamando que sus propias reflexiones sobre estética habían encontrado confirmación en la obra de aquel.

Nos explica Lilla que, en la década de 1920, Benjamin vivió una conversión al pasar de la especulación teológica al marxismo. En sus cartas, el marxismo aparece como un acto de "decisionismo". Ahora se llamaba a sí mismo materialista, se proclamaba marxista y apoyaba la política comunista. Pero su adhesión se limitó a una cuestión intelectual. En otoño de 1926 realizó un breve viaje a Moscú, pero su incursión al corazón de la revolución fue un fiasco político y personal: Moscú estaba muy lejos de ser una utopía, él no hablaba ruso y la mujer a la que fue a visitar y de la que estaba enamorado, Asja Lacis, tenía otros amantes. Ya en 1934, Benjamin envió a Scholem un bosquejo de su extraordinario ensayo sobre Kafka. Con este ensayo Scholem confirmó la certidumbre que tenía respecto a que los temas teológicos se volvían más confusos por su peculiar materialismo. Por su parte, Bertolt Brecht, con quien Benjamin había pasado el verano de 1934, se sintió desconcertado y desilusionado ante la reincidencia teológica perceptible en este ensayo. Es obvio que la adhesión de Benjamin al marxismo siempre estuvo íntimamente entrelazada con sus originales preocupaciones teológicas, lo que situó a Benjamin en una "tierra de nadie" intelectual, donde ni el teólogo Scholem ni 
el materialista Brecht conseguían alcanzarlo. No obstante, Theodor Adorno no lo creía así. Adorno sentía una profunda admiración por el trabajo de Benjamin y entendió su giro al marxismo como un signo de que allí subyacía una secularización productiva de su pensamiento. En 1933, Benjamin se mudó a París animado por Gretel Adorno, y la relación de los tres se tornó más íntima. Benjamin nunca hubiera sobrevivido a los años de exilio sin la ayuda desinteresada de Adorno. En 1927, Benjamin había comenzado su Proyecto u Obra de los Pasajes, un proyecto que lo absorbería durante los siguientes trece años. A su muerte quedó un caótico conjunto de notas, recortes, apuntes y ensayos fragmentarios. Bajo el influjo de Adorno el proyecto adoptó un tono y unas proporciones grandiosas. En 1929, Adorno lo consideró un modelo de su nueva teoría crítica. La Obra de los Pasajes parecía una descripción de las ruinas de la producción de los últimos años de un intelectual. Parte de la responsabilidad del naufragio de esta obra puede adjudicarse a Adorno, que presionó a Benjamin para que replantease el proyecto una y otra vez. Aunque colaborarían más tarde con Adorno en la publicación de la obra de Benjamin, tanto Scholem como Hannah Arendt lamentaron siempre los vínculos de su amigo con la Escuela de Frankfurt.

En otoño de 1939, Benjamin fue confinado, como alemán, en un campo francés para extranjeros. En junio de 1940, después de que los alemanes invadieran el norte de Francia, Benjamin huyó a Marsella. $\mathrm{Al}$ no encontrar manera de salir por mar, a comienzos de septiembre cruzó a pie los Pirineos junto a un grupo de refugiados y llegó al pueblo español de Portbou. Pero la guardia fronteriza española lo encontró y le anunció que lo devolvería a Francia a la mañana siguiente. Esa misma noche, en un hotel de Portbou, tomó una sobredosis de morfina y murió. Quiso el destino que, al día siguiente, el grupo sobreviviente consiguiera seguir su viaje llegando a Estados Unidos. Varios meses después, Hannah Arendt escapó de Francia a España llevando consigo un ensayo, una especie de pliego de últimas voluntades y un testamento intelectual titulado "Tesis de filosofía de la historia”, que Benjamin le había entregado antes de su intento de huida. Adorno decidió publicarlo, contra los deseos de Benjamin, en 1942, desde entonces se ha convertido en una de sus obras más polémicas. Las “Tesis” reflejan su apocalíptica visión de la política europea de finales de los años treinta y su desengaño ante la traición comunista que significó el pacto entre Hitler y Stalin. En un nivel más profundo, 
estas "Tesis" representan el último y dramático encuentro entre la metafísica teológica de Benjamin y el materialismo histórico.

El capítulo 4 está dedicado a "Alexandre Kojève". Alexandre Vladimirovitch Kojevnikov, que prefería ser llamado "Kojève”, fue un aristócrata ruso que se convirtió en uno de los estadistas y filósofos de la política más prestigiosos del siglo XX en Francia. Kojève dedicó toda su vida intelectual a la recuperación y explicación de la entonces desprestigiada filosofía de G. W. F. Hegel. A pesar de ser ruso, fue arquitecto de la reconstrucción europea de posguerra y reputado asesor de ministros y presidentes franceses. En la actualidad su obra ha alcanzado un peso considerable y se le ha dedicado una biografía importante. La discutida obra de Francis Fukuyama El último hombre y el fin de la historia (1992) difundió las ideas de Kojève sobre la política y la historia modernas ante una audiencia tremendamente amplia. Desde el punto de vista filosófico ha sido más importante la traducción de la correspondencia de Kojève con el filósofo Leo Strauss, publicada junto a una nueva edición de la ya clásica confrontación entre estos dos pensadores con respecto al tema de la tiranía.

Kojève nació en 1902 en el seno de una familia acomodada y bien relacionada de Moscú. Era sobrino de Vasili Kandinsky y su familia se movía en los círculos de la intelligentsia rusa más elevada. La revolución de octubre acabó con el mundo de los Kojevnikov. Al verse privado para estudiar decidió cruzar la frontera polaca en 1920. Llegó a Alemania y en 1926 se estableció finalmente en París. Desde entonces su vida tuvo dos facetas: la de filósofo solitario y la de funcionario de elevado nivel. Su vida intelectual comienza con su célebre seminario sobre Hegel, el cual definió de modo significativo el paisaje intelectual de la Francia del siglo XX. El seminario comenzó en 1933. En las conferencias de la década de 1930, publicadas con el título Introducción à la lecture de Hegel, sostiene, a lo largo de los años, el descubrimiento hegeliano: la lucha del ser humano por el reconocimiento es el motor de cualquier historia. Esta pugna se desarrolla en los individuos, en las clases y en las naciones; tanto en lo religioso como en lo intelectual. La vida intelectual de Kojève cambió abruptamente en 1939, cuando se acabaron las conferencias sobre Fenomenología y los alemanes invadieron Checoslovaquia. Pasó la guerra en Marsella, donde se le impidió seguir hasta Estados Unidos, y después de la liberación volvió a París. Allí comenzó su otra faceta cuando dos de sus alumnos le propusieron formar parte del gobierno 
como consejero de la oficina de relaciones económicas internacionales del Ministerio de Hacienda. Kojève aceptó el puesto y hasta su muerte, en 1968, fue un respetado consejero del Estado. En este lapso Kojève desapareció por completo de la escena intelectual de París.

Durante la "guerra fría" mantuvo una refinada neutralidad filosófica. En un manuscrito titulado "Esquisse d'une doctrine de la politique française", escrito en 1945, se describe el entorno de la Francia de posguerra y en él, Kojève trata de sentar las bases de una posible estrategia internacional basada en su lectura de la historia mundial. Lilla afirma que se trata de un documento casi visionario. Auffret demostró que las ideas del maestro ruso fueron una de las más importantes fuentes de la política francesa respecto a Europa y el tercer mundo durante casi veinte años. (Su papel fue fundamental en la formación de la Comunidad Económica Europea y en los acuerdos anteriores a la firma del GATT.) Kojève pasó años estudiando filosofía, lenguas orientales y religión en Heidelberg, donde completó una tesis dirigida por Karl Jaspers sobre el pensador ruso Vladimir Soloviov.

Para Kojève, la perspectiva de la deshumanización del hombre a causa del abandono de la búsqueda del saber o de la perfección moral era una posibilidad que la historia había hecho probable y con la que había que contar. Durante la guerra fría, su neutralidad entre el capitalismo de las democracias liberales y las dictaduras del socialismo estatalista estaba anclada en una profunda indiferencia con respecto a la posible deshumanización de sus congéneres, cuyos sufrimientos solo le concernían en la medida en que la pugna por el reconocimiento acababa en un triunfo susceptible de comprobarse en cambios históricos. El destino de los perdedores no tenía relevancia para él. Además, Kojève defendía que los regímenes totalitarios modernos podrían adelantar el trabajo de la historia y preparar el camino hacia un futuro mejor. Por fortuna, Kojève nunca ocupó ese puesto oficial que le hubiera permitido probar su audacia en este aspecto.

En el capítulo 5 el autor nos acerca al filósofo "Michel Foucault", cuya obra, nos dice Lilla, no deja a nadie indiferente. Hoy, casi dos decenios después de su muerte, sigue siendo imposible discutir desapasionadamente sus ideas y libros. Durante toda su vida Foucault reivindicó ser discípulo de Nietzsche, lo que para él parecía implicar que la actividad intelectual debe ser consecuencia de lo que uno es o trata de ser, y que esta vinculación no supone una debilidad. 
Miller ha escrito un libro de gran importancia que permite juzgar tanto al hombre Foucault como a la visión política que la moral de Nietzsche le inspiró. Paul-Michel Foucault nació en Poitiers en 1926. Su familia provenía de la burguesía católica acomodada. Tras ser testigo directo de la vergüenza de la ocupación y de la hipocresía de Vichy, en 1945 Foucault dejó la provincia y se trasladó a París, donde vivió hasta su muerte. Fue allí donde el joven estudiante descubrió la filosofía bajo la tutela de Jean Hyppolite, un reputado seguidor de Hegel que enseñaba en la École Normale Supérieure. Pero Foucault le daría la espalda al interesarse por pensadores como Nietzsche y Heidegger. En 1948 protagonizó un intento de suicidio, tras lo cual fue ingresado en una clínica privada. En su estudio bioráfico, James Miller llegó a la conclusión de que la fuente de sufrimiento de Foucault era su homosexualidad. Aunque lo que guió su derrotero intelectual no fue la homosexualidad como tal, sino la idea de la transgresión de las fronteras. En su estudio, Miller consiguió identificar la doble búsqueda de Foucault: la perspectiva de la sociedad moderna desde la mirada parcial del nietzscheano que ve la voluntad de poder en todas partes y la de la travesía de las fronteras de la experiencia que esta sociedad y su moral han mantenido apartada de nosotros.

Foucault aceptó de forma repentina un trabajo como profesor en Suecia en 1955. Aprovechó ese momento para empezar su tesis, que se convertiría en su obra más importante: Historia de la locura en la época clásica (1961). En 1958 aceptó un cargo cultural en Polonia. Después de permanecer dos años en Hamburgo, volvió a Francia en 1960. La primera vez que atrajo la atención pública fue como especialista, en 1961, cuando se publicó su tesis. Esta obra impresionó profundamente al tribunal académico de Foucault, que insistió en el carácter "mítico" y "alegórico" de la obra. Lilla añade que como trabajo de imaginación y como prolegómeno de la historia de la locura, es un libro extraordinariamente rico.

La reputación de Foucault como un académico apolítico continuó aumentando a comienzos del decenio de 1960. En 1963 publicó El nacimiento de la clínica. A esto siguió Las palabras y las cosas (1966), un denso estudio sobre las "ciencias humanas". Como la Historia de la locura en la época clásica, Las palabras y las cosas viene a señalar un alejamiento respecto del humanismo ilustrado en dirección a Nietzsche, Sade y los surrealistas. El libro se convirtió en un best seller. A raíz de mayo del 68, Foucault sustituyó sus preocupaciones académicas por la retórica antiintelectual del propagandista. 
El rápido cambio político en la escena intelectual francesa a mediados de los setenta tuvo en Foucault profundas consecuencias. Se encontró desorientado desde el punto de vista político e intelectual. Afirma Lilla que Miller intenta, y parcialmente consigue, interpretar el sentido de los últimos años de la vida de Foucault afrontando sus exploraciones sexuales, tanto de pensamiento como de acción, como si estuviesen profundamente relacionadas. Con esta ayuda es fácil integrar en el esquema de sus primeras investigaciones morales e históricas el último y menos entendido de sus proyectos, su Historia de la sexualidad (tres volúmenes, 1976-1984). Sea como sea, la cuestión nietzscheana acosa la biografía del filósofo. Su vida y sus obras muestran qué sucede cuando un pensador estrictamente privado, intoxicado por el ejemplo de Nietzsche y en lucha con sus demonios internos, los proyecta hacia la esfera política.

En el capítulo 6 nos encontramos con "Jacques Derrida”. La lista de filósofos franceses de peso que mantuvieron su obra alejada de las pasiones políticas del momento es breve. En esa lista se encuadra al padre de la deconstrucción, Jacques Derrida. Derrida adoptó una actitud escéptica ante los sucesos de mayo del 68 y el breve período de histeria maoísta en Europa. Declaraba ser de izquierdas, pero rehusaba dar explicaciones sobre el asunto. El pensamiento de Derrida es difícil de entender fuera de las controversias parisienses acerca de los legados del estructuralismo y el heideggerianismo. No obstante, en Estados Unidos sus ideas se introdujeron en la crítica literaria y ahora circulan en el entorno del posmodernismo académico, donde Derrida es considerado un clásico del canon posmoderno.

En la década que siguió a la Liberación (de Francia), la presencia hegemónica en la filosofía francesa fue Jean-Paul Sartre y la cuestión dominante fue el comunismo. Pero los jóvenes estudiantes, que intentaban escapar de la atmósfera de la guerra fría, abandonaron el último giro del compromiso político "existencial" impulsado por Sartre y se volvieron hacia una nueva ciencia social llamada estructuralismo. Tras este giro intentaron desarrollar una nueva aproximación a la filosofía, encabezados por quienes eran sus figuras más representativas, Michel Foucault y Jacques Derrida. A mediados de la década de 1970, la idea estructuralista se había transformado en un movimiento de liberación antiteológica que celebraba la diferencia allí donde la detectaba. François Dosse describe la doctrina de la deconstrucción de Derrida como "ultraestructuralismo". En Francia, la novedad de la deconstrucción residió en abordar los 
temas del estructuralismo -la diferencia, el Otro- con los conceptos y las categorías filosóficas de Martin Heidegger. En este punto, nos recuerda Lilla que Derrida se alineó con Heidegger y que hay que tener en cuenta esta decisión a favor de Heidegger para poder rastrear los problemas políticos de la deconstrucción.

Todo lo que se puede deducir del modo en que Derrida concibe las relaciones estrictamente políticas está contenido en Políticas de la amistad, el único de sus libros que lleva el término "política" en el título. Se basa en un seminario dictado en París entre 1988 y 1989, en el momento en que Europa veía tambalearse sus cimientos a causa del acelerado colapso del bloque oriental. Nos dice Lilla que casualmente asistió a ese seminario y que tuvo dificultades para entender hacia qué apuntaba Derrida. Su objetivo era mostrar que el pensamiento político de toda la tradición occidental ha sido distorsionado por el concepto de identidad. En el capítulo más argumentado del libro, Derrida examina la concepción política de Carl Schmitt, que describe la relación política como un vínculo de esencial hostilidad entre amigos y enemigos. Derrida no ve a Schmitt como un simple apologista del nazismo sediento de enfrentamientos, sino como a un profundo pensador que hizo explícitas las suposiciones implícitas en toda la filosofía política de Occidente. Desde este punto de vista, todas las ideologías políticas occidentales -fascismo, conservadurismo, liberalismo, socialismo, comunismo- parecen igualmente inaceptables. Pero, si tal como afirma en Políticas de la amistad, se puede transformar el lenguaje, también se puede transformar la política, aunque Derrida se muestra absolutamente imparcial en cuanto a qué podría acarrear eso. Pero en los noventa Derrida cambió sustancialmente de criterio. Concluyó que existía un concepto capaz de resistir la corrosión de la deconstrucción, y ese concepto era la "justicia”. En el otoño de 1989, Derrida fue invitado a dirigir un simposio en Nueva York sobre el tema "La deconstrucción y la posibilidad de justicia”. El objetivo de Derrida es demostrar que, aunque la deconstrucción puede y debe ser aplicada al derecho, no puede y no debe ser tomada para desvalorizar la idea de justicia. Según su perspectiva, el problema del derecho es que se funda y promulga sobre la base de la autoridad y, por lo tanto, reposa en la violencia.

En París, nos explica Lilla, las cosas han cambiado. Numerosos intelectuales franceses, estructuralistas en los años cincuenta, han empezado a entender que el vocabulario que una vez utilizaron para 
defender a las sociedades coloniales de la tiranía de Occidente se usa ahora para excusar los crímenes cometidos por los dictadores locales contra sus propios pueblos. El abandono del estructuralismo y de la deconstrucción no fue filosófico: al menos al principio, provenía de un rechazo moral que tuvo el higiénico efecto de restablecer las distinciones entre la filosofía pura, por una parte, y el compromiso político, por otra.

En el "Epílogo. La seducción de Siracusa", Lilla nos explica que existe un mito sobre Platón. Suele afirmarse que a él se le debe una propuesta temeraria: instituir, en las ciudades griegas, el gobierno de los "reyes filósofos". En 1934, cuando Martin Heidegger retomó la enseñanza tras su vergonzoso período como rector nazi de la Universidad de Friburgo, un colega ahora olvidado, para ahondar en el oprobio, le preguntó sarcásticamente: “¿De vuelta de Siracusa?”. No se podría haber formulado de modo más ingenioso y acertado esta observación, afirma Lilla. Platón viajó a Siracusa con la intención de instruir filosóficamente a su gobernante, pero la empresa fracasó, porque el tirano no supo convertirse en filósofo. Sin embargo, los objetivos de Platón y los de Heidegger eran del todo diferentes. Dionisio, el gobernante de Siracusa, es nuestro contemporáneo. A lo largo del último siglo ha tomado muchos nombres: Lenin y Stalin, Hitler y Mussolini, Mao y Ho, Castro y Trujillo, Amin y Bokassa, Sadam y Jomeini, etc. Las almas optimistas del siglo XIX creían que la tiranía era cosa del pasado. Después de todo, Europa había entrado en la modernidad y todos sabían que las complejas sociedades de este período, asociadas a los seculares valores democráticos, no podrían ser gobernadas según los antiguos medios despóticos. Sin embargo, la tiranía sobrevivió. La Europa continental alumbró dos grandes sistemas dictatoriales durante el siglo XX: el comunismo y el fascismo. Del mismo modo, también creó un nuevo tipo social para el que necesitamos un nuevo nombre: el del intelectual filotiránico. Algunos de los grandes pensadores de este período, cuya producción sigue vigente, se atrevieron a servir a modernos Dionisios. Sus historias son infames: Martin Heidegger y Carl Schmitt en la Alemania nazi; György Lukács en Hungría; quizá algunos otros.

Distinguidos profesores, talentosos poetas y periodistas influyentes unieron sus capacidades para convencer a todo el mundo de que los regímenes dictatoriales modernos eran liberadores y de que sus crímenes y excesos eran nobles, observados desde la óptica adecuada. Pero, ¿qué ocurre en la mente humana que la hace capaz de proclamar 
la defensa intelectual de un régimen dictatorial en pleno siglo XX? ¿Cómo se puede llegar a argumentar que la tiranía es algo bueno? En el siglo XX, el caso Heidegger es el más dramático ejemplo de cómo la memoria viva de la tradición, la filosofía o el amor a la sabiduría se transforma en amor a la tiranía. Los acontecimientos del siglo XX ofrecen la oportunidad de analizar extraordinarias manifestaciones intelectuales de filotiranía, cuyas fuentes no desaparecerán a pesar de que las circunstancias políticas sean menos extremas.

En el "Epílogo a la última edición. Sola fide", firmado en París, en junio de 2016, Lilla nos explica que Pensadores temerarios se publicó en Estados Unidos el 9 de septiembre de 2001, dos días antes de los atentados de al-Qaeda en Nueva York. De manera que, Lilla no podía haber previsto, señaló el fin de una era. La década que transcurrió entre la caída del Muro de Berlín y la caída de las Torres Gemelas fue un período de introspección y autosatisfacción, cualidades que este libro comparte hasta cierto punto. Nadie había anticipado la rápida fragmentación del Imperio soviético, el giro igualmente rápido de la Europa del Este hacia la democracia, o el marchitar de los movimientos revolucionarios. Los dramáticos acontecimientos del 11 de septiembre llevaron los años noventa a un final abrupto y colocaron un cordón sanitario intelectual a su alrededor. Nunca desde el final de la Segunda Guerra Mundial, y quizá desde la Revolución rusa, el pensamiento político de Occidente ha parecido tan superficial y desorientado. Carecemos de los conceptos e incluso del vocabulario adecuado para describir el mundo en el que nos encontramos. Y de manera todavía más preocupante, carecemos de conciencia de que carecemos de ello. Una nube de testaruda ignorancia parece haberse posado sobre nuestra vida intelectual. Esto, le parece a Lilla, es el proceso más significativo que ha sucedido desde que se publicó Pensadores temerarios, y lo primero que necesitamos entender sobre el presente. Lilla finaliza diciendo que necesitamos que se nos recuerden muchas cosas. Entre ellas que el atractivo de la tiranía no es la única fuerza que aparta a los intelectuales de su camino. El autoengaño asume infinitas formas. Una década y media después de su primera edición, la esperanza de Lilla es que Pensadores temerarios sea ese recordatorio.

Elisabet F. Gutiérrez

UNED

e-mail: <efilgueir12@alumno.uned.es> 